\title{
Development and application of the SBR guidelines of the Conference of European Statisticians
}

\author{
Norbert Rainer \\ Private Consultant, Austria \\ E-mail: norbert_rainer@aon.at
}

\begin{abstract}
Statistical business registers (SBR) play a central role in the production of economic statistics. Traditionally, the functions of an SBR have been to provide a population of statistical units from which frames and samples for economic surveys are drawn. Today, however, the SBR fulfils various other roles in relation to the changing environment in which economic statistics are produced. In the light of the growing demand for high quality and more internationally comparable economic statistics, the Bureau of the Conference of European Statisticians established in November 2011 a Task Force to produce a set of international guidelines and recommendations to assist countries in developing and maintaining their SBR. The guidelines were endorsed by the Conference of European Statisticians in April 2015 and published in September 2015 [1].

The paper provides an overview of the guidelines, which aim to provide practical guidance on establishing and maintaining an SBR and on register's important role in the production of economic statistics more generally. The paper explains the background for developing the guidelines and the goals followed, i.e. that the guidelines should give recommendations for implementation of sound methods and good practices, provide examples of good practice from countries and, where suitable, build on existing international manuals and guidelines relevant for SBRs.
\end{abstract}

Keywords: Statistical business registers, economic statistics

\section{Introduction}

Over the last decade, the growing demand for better, more detailed, more consistent, and internationally comparable economic statistics has put focus on statistical business registers (SBRs) and their role in the production of economic statistics. Furthermore, the way in which economic units organise their activities has also changed considerably in recent decades, especially concerning the key importance of enterprise groups and generally the internationalisation of economic relations (globalisation). These changes have had considerable effects on the concepts, tasks, development and maintenance of SBRs and they present a major challenge for national statistical offices.

The traditional and still most important role of SBRs is to provide sample frames for business statistics. The quality of the SBR is therefore crucial for the qual- ity of business statistics and the statistics based upon information from the SBR, including the national accounts. However, SBRs are more powerful today: they include additional variables, provide links to administrative and other data sources, provide identification and links between the economic units for micro-data linking, support survey processes, document response burden and - last but not least - are powerful detailed databases that support the compilation of certain statistics, especially business demography data. Thus, the SBRs today serve as the general backbone for economic statistics.

The need for international guidance on SBRs and for recommendations on good practices has been raised by countries participating in the meetings of the Wiesbaden Group on Business Registers and in the joint UNECE/Eurostat/OECD Expert Group on Business Registers. At its meeting in November 2011 the Bu- 
reau of the Conference of European Statisticians (CES) recognised a great diversity in the content and usability of SBRs among countries and regions, while the demand for high quality and international comparable business statistics was growing. Given this background, the Bureau decided that a set of international guidelines would be useful, and agreed to establish a Task Force. The Task Force, which was chaired by Statistics Austria, took up its work in early 2012 and finished the draft guidelines in spring 2015. The guidelines were endorsed by the Conference of European Statisticians in April and were published in September 2015 by the UNECE.

\section{Goals and approaches applied in developing the guidelines}

According to the Terms of Reference, the SBR Task Force had to:

- Provide practical guidance on core issues of establishing and maintaining the SBR.

- Clarify concepts and definitions.

- Provide guidance on the use of administrative and other sources for the establishment and updating of the SBR.

- Provide guidance on how to use the SBR in its own right for production of statistics and how information from the SBR can be combined with information from other statistical registers, administrative records or surveys to produce new statistics.

- Provide guidance on the role of SBR in the modernisation of statistical production and services.

The guidelines had to be targeted at both developed and less developed statistical systems and provide not just conceptual issues, but also practical guidance and recommendations on the establishment and maintenance of an SBR. The guidelines had to include country experiences and case studies, be consistent with other international manuals and guidelines and take into account other international work in the area of statistical business registers, in particular the Business Registers Recommendations Manual, Eurostat (2010) [2] and the Guidelines for Building Statistical Business Registers in Africa, African Development Bank (2012) [3].

Given the central role of the SBR in the establishment of economic statistics and its use in different departments of statistical offices, the Task Force targeted the guidelines not only at SBR management and staff, but also at the staff of business and economic statistics, staff dealing with respondent relations and staff dealing with administrative authorities that deliver data for statistical purposes.

While a variety of international manuals and guidelines, such as the classification manuals, the manual on the use of administrative data sources, on the informal sector, on business demography, etc., have been taken into account, the SNA 2008/ESA 2010 provides the conceptual framework of the SBR guidelines.

The Task Force also considered it important to receive feedback from countries during the process of developing and drafting the guidelines. Therefore, at the meetings of the Wiesbaden Group on Business Register $(2012,2014)$ and of the joint UNECE/Eurostat/OECD Expert Group on Business Registers (2013) draft outlines or already existing versions of draft chapters were presented and discussed. These groups were also invited to provide written comments. In addition, in March-April 2015 the draft guidelines were circulated for official consultation to all members of the CES. The final version incorporating comments and proposals received during the consultation was submitted to the 2015 CES plenary session and endorsed by countries.

\section{Overview of the guidelines}

A detailed description of the content of the guidelines cannot be provided here. There is room only for the basic ideas of the structure of the guidelines. The first main chapter of the guidelines explains the various roles of SBRs. It was considered important that these roles - in total eight were distinguished - were already described at the very beginning. This should make the reader aware of the power of SBRs and should help in better understanding the conceptual details. The usability of an SBR for its backbone role depends to a considerable extent on the coverage of the register and the statistical units. Thus, Chapter 3 deals with the coverage of SBRs in the context of the various institutional unit types and sectors of the economy and provides recommendations for a minimum coverage. Chapters 4 and 5 deal with the statistical units that are the core entities in an SBR. The complexity of the statistical units arises from the fact that the statistical unit may not coincide with the actual organisation of the business. This might for instance be the case for the enterprise unit that may be comprised of more than one legal unit.

Data sources and maintenance concepts for the establishment and maintenance of SBRs are discussed 
Table 1

Overview of the content of the guidelines

Structure of the guidelines
Chapter 1 - Introduction
Chapter 2 - Roles of the SBR

Chapter 3 - Coverage of the SBR

Chapter 4 - Units in the SBR

Chapter 5-Characteristics of units

Chapter 6 - Data sources for the SBR

Chapter 7 - Maintenance of the SBR

Chapter 8 - Survey frame methodology

Chapter 9 - Dissemination

Chapter 10 - Quality

Chapter 11 - Key considerations in establishing an SBR

Chapter 12 - Topics for future work and research

Annex A: Characteristics of units by unit type Annex B: International classifications

Annex C: Examples of statistical business registers Annex D: Examples relating to SBR quality

Annex E: Additional concepts and procedures Glossary

Main content

Definition and concept of an SBR; use of the SBR; aims and overview of the guidelines; terminology.

Description and explanation of eight roles of an SBR: SBR live register, SBR snapshots, SBR survey frame, SBR survey support, SBR statistics, SBR information source, SBR international data exchange, SBR in modernisation of statistical production and services.

Description and explanation of key concepts (production boundary, market - non-market, informal sector); SBR coverage by types of institutional units; recommendation of a minimum coverage.

Definition of the main statistical units relevant for SBR (enterprise group, enterprise, establishment/local kind of activity units, local unit; specific units in certain sectors of the economy; special purpose units.

Characteristics for each kind of statistical unit by categories: identification and contact, demographic characteristics, economic/stratification characteristics, relationships and links between units, relationships and links to other registers.

Discussion and recommendations concerning various kinds of data sources: administrative data, statistical sources and survey feedback, commercial and other data sources; focus on administrative data sources

Key aspects of a maintenance strategy; recommendations on practical implementation; maintenance concepts, such as handling demographic events, continuity rules, dealing with conflicting information, error correction.

Explains the backbone role of an SBR for economic surveys: survey frame methodology; snapshots and frozen frames; coverage and other frame errors.

Dissemination of economic statistics directly based on an SBR: business demography; micro-data dissemination; confidentiality considerations.

SBR quality dimensions; quality assessment methods; quality indicators; quality policy and improvement.

Provides guidance on the planning, governance, organisational, legal and technical (IT systems) factors for the establishment or redesign/re-engineering an SBR.

Topics for future work and research grouped by eight domains: Statistical units and profiling. SBR as backbone, use of administrative sources, use of new data sources, international trade and globalisation, development of new statistics, methodological developments, and international comparability.

Detailed list of characteristics for each type of unit.

Coding of units by ISIC Rev. 4 and the classification of institutional sectors.

Examples from Denmark, Costa Rica, Canada, Georgia and Malaysia.

Examples from Italy, Columbia and Netherlands.

Register based census, calculating check digits for an identification number.

Definition of about 130 terms. in Chapters 6 and 7. Today the main data sources are administrative data, especially taxation and social security data. The chapter gives advice on use of administrative data, cooperation with administrative authorities and problems that might occur when administrative data are used for statistical purposes. Chapter 7 provides the basic considerations in the establishment of a maintenance strategy that is based on user needs, especially those of the survey staff. Demographic events, continuity rules, handling of changes in the characteristics and the treatment of errors are main issues dealt with in this chapter.

The survey frame role of SBRs is explained in more detail in Chapter 8 on the survey frame methodology and how the SBRs should contribute to the frame design for business statistics. The increasing role of SBRs as information databases that could be used directly for deriving statistics (business demography, census type statistics) is discussed in Chapter 9. This chapter deals also with issues related to dissemination, such as confidentiality.

The next two chapters deal with overall issues of the management of SBRs. Chapter 10 discusses the crucial issue of register quality: it describes the SBR quality dimensions, explains methods for quality assessment, proposes some quality indicators and outlines a quality 
Table 2

Overview of the main answers to the questionnaire

\begin{tabular}{|c|c|}
\hline Question & Main replies \\
\hline $\begin{array}{l}\text { Question } 1 \text { - Promotion of the guidelines in } \\
\text { your office } \\
\text { (Actions taken in order to promote the } \\
\text { guidelines in your office) }\end{array}$ & $\begin{array}{l}\text { - Distribution of hard/electronic copies to the SBR staff } \\
\text { - Basis for internal discussions on specific issues } \\
\text { - Help for IT experts to better understand the rationale of SBRs } \\
\text { - Used in training courses and for new staff }\end{array}$ \\
\hline $\begin{array}{l}\text { Question } 2 \text { - Implementation of the guide- } \\
\text { lines } \\
\text { (Actions that were set in your register sys- } \\
\text { tem and/or concepts that were originating } \\
\text { from or based on the guidelines) }\end{array}$ & $\begin{array}{l}\text { - Used as reference of SBR redesign processes } \\
\text { - Used in reviewing of the compliance of national definitions/concepts with the international def- } \\
\text { initions/concepts } \\
\text { - Guidelines are themselves mainly not an originator of implementation processes but are of help } \\
\text { in case actions are considered/planned } \\
\text { - Furthermore, the guidelines were of help in various conceptual issues and practices, such as } \\
\text { statistical identifiers, snapshots and frame methodology, maintenance concepts and procedures, } \\
\text { quality indicators, access to administrative data }\end{array}$ \\
\hline
\end{tabular}

Question 3 - Future work and research top- Statistical units and profiling:

ics

- Nearly all countries reported current or planned activities, with focus on profiling large and com(Work done recently or planned on the spe- $\quad$ plex enterprises, delineation and implementation of enterprises groups and enterprises, integratcific topics of future work and research according to Chapter 12) 
Table 2

continued

\begin{tabular}{ll}
\hline Question & Main replies \\
\hline Question 4-Other comments and proposals & - Guidelines are a useful reference tool and its usage will be promoted \\
& - More guidance requested especially on statistical units, software and information technology \\
& - More practical cases and guidance in various areas \\
& - Expectation that the Guidelines will be updated on a regular basis \\
& - More language versions helpful \\
& - Organisation of seminars, workshops, training courses and technical assistance
\end{tabular}

improvement policy. Chapter 11 on key considerations in establishing an SBR may be of particular interest for countries developing or re-engineering an SBR. It deals with issues, such a planning, governance, organisational and IT considerations.

The last Chapter 12 is different from the preceding ones as it briefly describes topics for further work and research. The topics identified refer mainly to current or future issues that are posing major challenges. It is hoped that experiences will be shared among countries and common development projects be encouraged.

Table 1 provides an overview of the content of the guidelines, including the various annexes.

\section{Application of the guidelines}

In September 2016 - just one year after the publication of the guidelines - a questionnaire was sent to the members of the Wiesbaden Group on Business Registers and to the CES member countries in order to gather some initial information on how the guidelines were received by the countries. Thirty-two countries replied to this questionnaire. The questionnaire was developed as one of the follow-up measures concerning implementation of the guidelines. Table 2 provides an overview of the main answers to the four questions.

\section{Further developments}

In 2015 when endorsing the Guidelines on Statistical Business Registers, the Conference of European Statisticians also encouraged work on the topics of the research agenda listed in Chapter 12 of the guidelines and on promoting the guidelines and their implementation.

To follow-up on the CES proposals, the Steering Group of the Wiesbaden Group agreed to adapt their template for the annual Country Progress Reports to align it with the structure of the guidelines. This should help to receive answers from which information on the implementation of the guidelines and the efforts made on topics for future work and research can be drawn. The Country Progress Reports are submitted by most of the countries that participate in the meetings of the Wiesbaden Group and the Group of Experts on Business Registers. The Expert Group on Business Registers will follow-up on the research and implementation issues at its biennial meetings jointly organized by UNECE, Eurostat and OECD. To help in promoting the recommendations, the guidelines were translated into Russian in 2016. In 2017 the guidelines were translated into Chinese by the National Bureau of Statistics of China.

In March 2017 the UN Statistical Commission (UNSC) reiterated the importance of SBRs and underlined the need for capacity building activities in this area for developing countries. To this end, the UNSC agreed to initiate an update of the guidelines for global endorsement, taking into account the needs of countries with less developed statistical systems and incorporating practical guidance and country cases applicable to a broad range of statistical systems. The update will be tasked to a Committee of Experts with broad geographical representation.

\section{Acknowledgments}

Carsten Boldsen, UNECE, and Michael Colledge provided useful comments for the drafting of the paper.

\section{References}

[1] United Nations Economic Commission for Europe, Guidelines on Statistical Business Registers, New York and Geneva, 2015, http://www.unece.org/index.php?id=40574\&L=0, English and Russian.

[2] Eurostat, Business Register Recommendations Manual, 2010 edition. http://ec.europa.eu/eurostat/ramon/statmanuals/files/ KS-32-10-216-EN-C-EN.pdf.

[3] African Development Bank, Guidelines for Building Statistical Business Registers in Africa, 2014, https://www.afdb.org/ fileadmin/uploads/afdb/Documents/Project-and-Operations/ Guidelines_for_Building_Statistical_Business_Registers_in_ Africa.pdf. 